\title{
Atmospheric Acid Gases in Tokushima, Japan, Monitored with Parallel Plate Wet Denuder Coupled Ion Chromatograph
}

\author{
Masaki TaKeuChI, ${ }^{* \dagger}$ Yuki MiYaZaKI, ${ }^{* *}$ Hiromichi TsunOda,** and Hideji TanaKA* \\ *Institute of Health Biosciences, The University of Tokushima Graduate School, 1-78-1 Shomachi, \\ Tokushima 770-8505, Japan \\ **Graduate School of Pharmaceutical Sciences, The University of Tokushima, 1-78-1 Shomachi, \\ Tokushima 770-8505, Japan
}

\begin{abstract}
During the summer of 2011 and winter of 2012, we continuously measured trace acid gas concentrations in Tokushima, Japan, using a parallel plate wet denuder coupled ion chromatograph. The average concentrations of hydrochloric acid $(\mathrm{HCl})$, nitrous acid $(\mathrm{HONO})$, nitric acid $\left(\mathrm{HNO}_{3}\right)$, and sulfur dioxide $\left(\mathrm{SO}_{2}\right)$ were, respectively, 0.54, 1.20, 1.17, and $3.22 \mu \mathrm{g} \mathrm{m}^{-3}$ in the summer, and $0.09,1.06,0.46$, and $5.11 \mu \mathrm{g} \mathrm{m}^{-3}$ in the winter. In the summer, concentrations of all the acid gases increased after sunrise and showed a strong diurnal pattern with daytime maxima and nighttime minima, but the time at which concentration levels began to increase and the pace of increase differed among the acid gases. The concentration of HONO increased sharply immediately after sunrise, while concentrations of the other three gases began increasing about one and half hours later. $\mathrm{SO}_{2}$ showed the fastest rate of increase, followed by $\mathrm{HNO}_{3}$ and $\mathrm{HCl}$. These differences were likely attributable to the formation processes of gaseous substances.
\end{abstract}

(Received September 5, 2012; Accepted November 6, 2012; Published January 10, 2013)

\section{Introduction}

Measurements of atmospheric acid gases have been taken in regions across the globe in order to study their impact on health and the environment. ${ }^{1,2}$ The anthropogenic sources of some acid gases include direct emissions from power plants, automobiles, and factories. ${ }^{3-5}$ Volcanic activity emits a significant amount of $\mathrm{HCl}$ and $\mathrm{SO}_{2}{ }^{6,7}$ The reaction of $\mathrm{HNO}_{3}$ with sea-salt particles is also a major source of $\mathrm{HCl}^{5}$ In the atmosphere, $\mathrm{HNO}_{3}$ and HONO are formed as a by-product the photochemical reaction of nitrogen compounds. ${ }^{8,9}$ Conventional filter-based methods are widely used for the collection of water-soluble acid gases. These simple methods, however, expose the positive and negative artifacts during air sampling, ${ }^{10-12}$ and cannot provide the sufficient time resolution needed to investigate the circadian variation of objective substances. Diffusion denuder techniques coupled with an analysis system such as ion chromatograph enable nearreal-time monitoring of multicomponent gases. ${ }^{13-16}$ We recently reported on a parallel plate wet denuder coupled ion chromatograph (PPWD-IC), which allows for highly sensitive and high time resolution monitoring of trace acid gases in an industrial cleanroom environment. ${ }^{17}$ With PPWD-IC, we continuously measured the concentrations of atmospheric $\mathrm{HCl}$, $\mathrm{HONO}, \mathrm{HNO}_{3}$, and $\mathrm{SO}_{2}$ in Tokushima, Japan. We discuss here the seasonal/circadian variations of acid gases using the high time resolution data.

† To whom correspondence should be addressed.

E-mail: masaki.takeuchi@tokushima-u.ac.jp

\section{Experimental}

During August 18 - 31 in 2011 and February $6-19$ in 2012, the ambient air was sampled from the fourth-floor north window (12 $\mathrm{m}$ above ground level) of a six-story building on the campus of the University of Tokushima, Tokushima, Japan $\left(34^{\circ} 04^{\prime} \mathrm{N}\right.$, $\left.134^{\circ} 30^{\prime} \mathrm{E}\right)$. The sampling site is surrounded by Mt. Bizan $(277 \mathrm{~m}$ above sea level) to the south, and is located about $8 \mathrm{~km}$ west of the Kii Channel. To the north is a busy road, National Route 192 (average traffic volume per day, approximately 34704 cars on weekdays).

The PPWD-IC was used for the continuous measurement of $\mathrm{HCl}, \mathrm{HONO}, \mathrm{HNO}_{3}$, and $\mathrm{SO}_{2}$ with 15 min time resolution. Details of the PPWD-IC have been described previously. ${ }^{17,18}$ In short, the PPWD is composed of two textured Plexiglas plates and a Teflon spacer (each with a $6 \times 42 \mathrm{~cm}$ active area, separated by $0.3 \mathrm{~cm}$ ). The air sample is aspirated from the bottom of the PPWD at $5 \mathrm{dm}^{3} \mathrm{~min}^{-1}$. The denuder liquid $\left(0.5 \mathrm{mmol} \mathrm{dm}^{-3}\right.$ $\mathrm{H}_{2} \mathrm{O}_{2}$ ) is delivered to flow down the inner plates at $0.25 \mathrm{~cm}^{3} \mathrm{~min}^{-1}$ plate ${ }^{-1}$. This diluted $\mathrm{H}_{2} \mathrm{O}_{2}$ enables the detection of collected $\mathrm{SO}_{2}$ as sulfate, with much less production of nitrite and nitrate from $\mathrm{NO}_{\mathrm{x}} \cdot{ }^{19}$ The entire PPWD effluent is sent to one of two anion concentrators (TAC-2, Dionex) that are connected to a 10-port injection valve (Cheminert $\mathrm{C} 2$, Valco Instruments). After 15 min sample loading, the analyte is determined by means of a Dionex ICS 1500 ion chromatograph (AG20 2-mm guard column, AS20 2-mm separation column, ASRS300 2-mm electrodialytic suppressor, CRD 2-mm carbon dioxide removal device, DS6 heated conductivity detector, Chromeleon 6.7 data system, and $15 \mathrm{mmol} \mathrm{dm}^{-3} \mathrm{KOH}$ eluent).

The data for temperature, relative humidity, sunshine, sunrise and sunset in Tokushima were provided by the Tokushima Local 

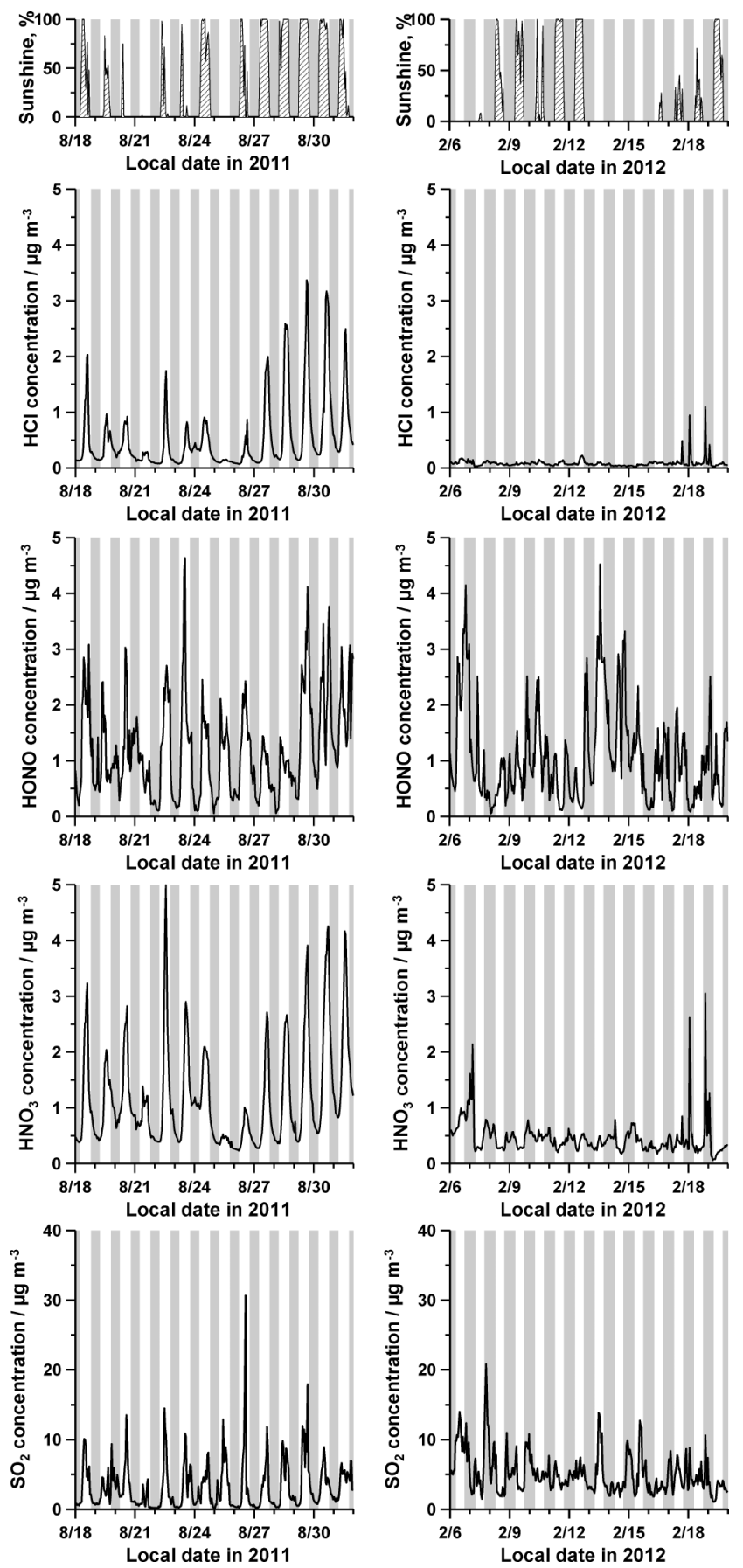

Fig. 1 Temporal variations of atmospheric acid gas concentrations and sunshine during summer (left, August 18 - 31 in 2011) and winter (right, February 6-19 in 2012) in Tokushima, Japan. The X-axis indicates midnight of the date. The shaded regions are the nighttime hours (sunset to sunrise). Sunshine shows the percentage of sunshine per hour.

Meteorological Observatory, which was located about $3.5 \mathrm{~km}$ east from the sampling site.

\section{Results and Discussion}

Acidic gas concentrations in summer and winter

Figure 1 shows the temporal variations of $\mathrm{HCl}, \mathrm{HONO}, \mathrm{HNO}_{3}$, and $\mathrm{SO}_{2}$ concentrations along with sunshine data. The average acid gas concentration during the summer and winter were, respectively, $0.54 \pm 0.65$ and $0.09 \pm 0.12 \mu \mathrm{g} \mathrm{m}^{-3}$ for $\mathrm{HCl}$, $1.20 \pm 0.92$ and $1.06 \pm 0.90 \mu \mathrm{g} \mathrm{m}^{-3}$ for $\mathrm{HONO}, 1.17 \pm 0.93$ and $0.46 \pm 0.41 \mu \mathrm{g} \mathrm{m}^{-3}$ for $\mathrm{HNO}_{3}$, and $3.22 \pm 3.72$ and $5.11 \pm$ $3.18 \mu \mathrm{g} \mathrm{m}^{-3}$ for $\mathrm{SO}_{2}$. The $\mathrm{HCl}$ and $\mathrm{HNO}_{3}$ concentrations were higher during the summer than winter, the summer/winter concentration ratio $(\mathrm{S} / \mathrm{W})$ being 6.0 and 2.5 , respectively. Our sampling site was located near the ocean. Therefore, it is possible that the reaction of $\mathrm{HNO}_{3}$ with $\mathrm{NaCl}$ in sea-salt particles increased, and resulted in higher $\mathrm{HCl}$ concentrations during the summer. ${ }^{20}$ The formation of $\mathrm{NH}_{4} \mathrm{Cl}$ particles is strongly suppressed by high temperatures. ${ }^{21,22}$ This might be another reason that the $\mathrm{HCl}$ concentration was higher during the summer than winter. The $\mathrm{HNO}_{3}$ is produced as a by-product of the photochemical reaction of the $\mathrm{OH}$ radical and nitrogen compounds such as $\mathrm{NO}_{2}$ contained in vehicular exhaust, ${ }^{8}$ thereby the $\mathrm{HNO}_{3}$ concentration is strongly influenced by traffic volume. Horng and Cheng ${ }^{23}$ reported that the $\mathrm{HNO}_{3}$ concentrations at a site near an expressway were several times higher than at a site some distance form an expressway during the daytime. As a densely trafficked road abutted on our sampling site, there was not much difference between traffic volumes during summer and winter. Hence, the $\mathrm{OH}$ radicals produced by higher solar radiation intensity may have accelerated $\mathrm{HNO}_{3}$ formation in the summer. Contrary to the seasonal trends for $\mathrm{HCl}$ and $\mathrm{HNO}_{3}$, the $\mathrm{SO}_{2}$ concentration was lower during summer than winter $(\mathrm{S} / \mathrm{W}$, 0.6), and the HONO concentration during summer was comparable with winter $(\mathrm{S} / \mathrm{W}, 1.1)$. The primary source of atmospheric $\mathrm{SO}_{2}$ is the combustion of fossil fuels, ${ }^{4}$ thus the $\mathrm{S} / \mathrm{W}$ of $\mathrm{SO}_{2}$ might reflect the amount of fuel used during each sampling period. Moreover, higher temperatures and relative humidity might enhance the conversion of $\mathrm{SO}_{2}$ to particulate $\mathrm{SO}_{4}{ }^{2-}$ during summer. ${ }^{20}$

In summer, concentrations of all the acid gases showed a strong diurnal pattern with daytime maxima and nighttime minima as shown in Fig. 1. Meanwhile in winter, acid gas concentrations did not show a distinct shift as in summer. Worth noting is that the variation of $\mathrm{HCl}$ in summer is quite similar to that of $\mathrm{HNO}_{3}$. This point will be examined later again. Another interesting finding was that the $\mathrm{SO}_{2}$ concentration in summer reached near-zero values during the nighttime, while the $\mathrm{SO}_{2}$ concentration in winter did not decrease as in summer. The heating fuel used in winter was likely the reason for relatively high residual levels of $\mathrm{SO}_{2}$ throughout the day.

\section{Circadian variations of acid gases during summer season}

Next, we examine the variation of acid gases during the summer in more detail. Figure 2 a shows the circadian variation of acid gas concentrations during the summer. Each plot in Fig. 2a shows the average level of two weeks of data. In order to easily compare the variations of gas concentrations, the relative concentration ratio, $R C R$, was calculated by Eq. (1) and the circadian variation of $R C R$ is shown in Fig. $2 \mathrm{~b}$.

$$
R C R=\left(C-C_{\min }\right) /\left(C_{\max }-C_{\min }\right) \times 100 \%
$$

where $C$ is the acid gas concentration, $C_{\min }$ and $C_{\max }$ are the minimum and maximum acid gas concentration measurements in summer $\left(0.15\right.$ and $1.43 \mu \mathrm{g} \mathrm{m}^{-3}$ for $\mathrm{HCl}, 0.30$ and $2.04 \mu \mathrm{g} \mathrm{m}^{-3}$ for $\mathrm{HONO}, 0.47$ and $2.67 \mu \mathrm{g} \mathrm{m}^{-3}$ for $\mathrm{HNO}_{3}, 0.79$ and $8.82 \mu \mathrm{g} \mathrm{m}^{-3}$ for $\mathrm{SO}_{2}$, respectively). Although all the acid gases showed higher levels of $R C R$ during daytime, the $R C R$ for HONO increased sharply immediately after sunrise. The levels of HONO RCR peaked around 9:00 and remained constant until 14:00, then decreased gradually through midnight but remained 
a)

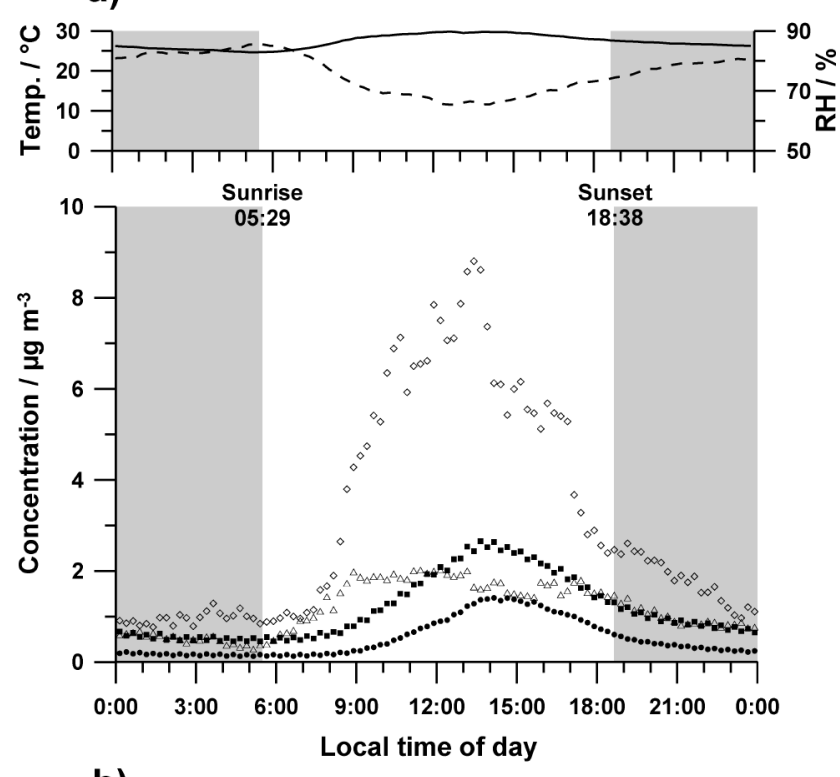

b)

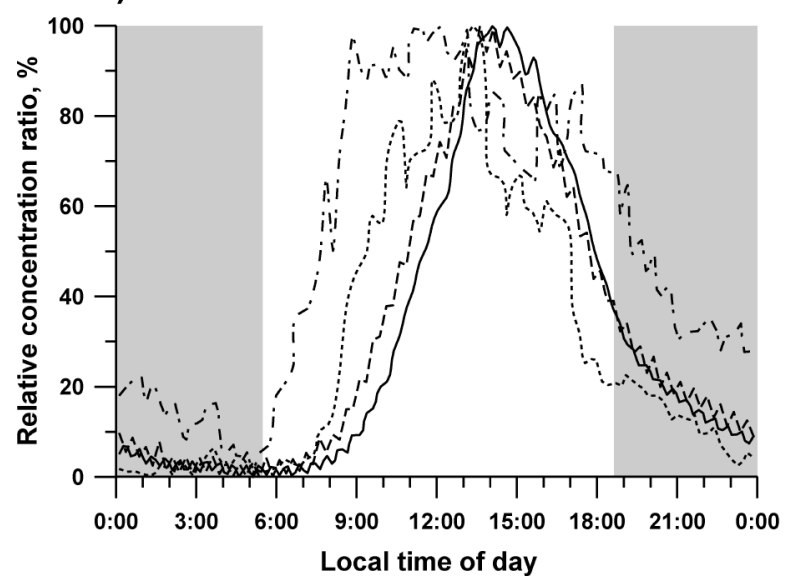

Fig. 2 Circadian variations of average a) atmospheric acid gas concentration and b) relative concentration ratio during summer (August 18 - 31 in 2011) in Tokushima, Japan. The temperature (solid line) and relative humidity (dashed line) are also shown as references in the upper part in Fig. 2a. The relative concentration ratio was calculated by Eq. (1). (a) Solid circle, $\mathrm{HCl}$; triangle, $\mathrm{HONO}$; solid square, $\mathrm{HNO}_{3}$; diamond, $\mathrm{SO}_{2}$. (b) Solid line, $\mathrm{HCl}$; dashed-dotted line, $\mathrm{HONO}$; dashed line, $\mathrm{HNO}_{3}$; dotted line, $\mathrm{SO}_{2}$.

relatively high compared to other acid gases. This circadian variation of HONO was different from the diurnal pattern with daytime minima and nighttime maxima published in some other studies. ${ }^{24,25}$ Recently, Kleffmann ${ }^{9}$ proposed three new photochemical daytime sources of HONO: formation on surfaces treated with $\mathrm{HNO}_{3}$, reduction of $\mathrm{NO}_{2}$ on organic surfaces, and gas phase photolysis of ortho-substituted nitroaromatics. Although the daytime HONO source is not fully explored, it is possible that the above reactions might have resulted in higher concentration levels during daytime. The increase in $R C R$ for $\mathrm{SO}_{2}, \mathrm{HNO}_{3}$ and $\mathrm{HCl}$ began around 7:00, with that for $\mathrm{SO}_{2}$ showing the fastest rate of increase, followed by $\mathrm{HNO}_{3}$ and $\mathrm{HCl}$. The $\mathrm{SO}_{2} R C R$ increase might be due to increasing direct emissions from anthropogenic sources in the morning. In Fig. 2a, the $\mathrm{HCl}$ variation appears to be the corresponding pattern to the $\mathrm{HNO}_{3}$. However, by examining the $R C R$ in Fig. 2b, a time lag in the rates of increasing $R C R$ between them was revealed. These results suggest that $\mathrm{HNO}_{3}$ is first formed by the homogeneous reaction of $\mathrm{NO}_{2}$ with $\cdot \mathrm{OH}$, and then $\mathrm{HCl}$ is formed by the reaction of the produced $\mathrm{HNO}_{3}$ with particulate $\mathrm{NaCl}$, as expressed below,

$$
\begin{aligned}
& \mathrm{NO}_{2}+\cdot \mathrm{OH} \rightarrow \mathrm{HNO}_{3}, \\
& \mathrm{HNO}_{3}+\mathrm{NaCl} \text { in sea-salt } \longrightarrow \mathrm{HCl}+\mathrm{NaNO}_{3} .
\end{aligned}
$$

In the summer, a strong correlation $(r=0.874)$ was obtained between the concentrations of $\mathrm{HCl}$ and $\mathrm{HNO}_{3}$. In addition, the correlations between the temperature and the concentrations of $\mathrm{HCl}$ and $\mathrm{HNO}_{3}$ in summer were relatively high $(r=0.737$ for $\mathrm{HCl}$ and $r=0.698$ for $\mathrm{HNO}_{3}$ ). These results support that the reactions of Eqs. (2) and (3) were dominant for the $\mathrm{HCl}$ and $\mathrm{HNO}_{3}$ by-product formations during the summer season.

\section{Acknowledgements}

This study was partly supported by the Grant-in-Aid for Research Activity Start-up (20850027) and the Grant-in-Aid for Young Scientists (B) (23710009) from the Japan Society for the Promotion of Science (JSPS).

\section{References}

1. J. A. Sarnat, P. Koutrakis, and H. H. Suh, J. Air Waste Manage. Assoc., 2000, 50, 1184.

2. J. A. Sarnat, K. W. Brown, J. Schwartz, B. A. Coull, and P. Koutrakis, Epidemiology, 2005, 16, 385.

3. N. Kaneyasu, H. Yoshikado, T. Mizuno, K. Sakamoto, and M. Soufuku, Atmos. Environ., 1999, 33, 1745.

4. D. G. Streets and S. T. Waldhoff, Atmos. Environ., 2000, $34,363$.

5. A. Bari, V. Ferraro, L. R. Wilson, D. Luttinger, and K. Husain, Atmos. Environ., 2003, 37, 2825.

6. T. Mori, K. Notsu, Y. Tohjima, and H. Wakita, Geophys. Res. Lett., 1993, 20, 1355.

7. T. Jurkat, C. Voigt, F. Arnold, H. Schlager, H. Aufmhoff, J. Schmale, J. Schneider, M. Lichtenstern, and A. Dörnbrack, J. Geophys. Res., 2010, 115, D00L17.

8. A.-M. N. Kitto and R. M. Harrison, Atmos. Environ., 1992, $26 A, 235$.

9. J. Kleffmann, ChemPhysChem, 2007, 8, 1137.

10. C. L. Benner, D. J, Eatough, N. L. Eatough, and P. Bhardwaja, Atmos. Environ., 1991, 25A, 1537.

11. X. Zhang and P. H. McMurry, Environ. Sci. Technol., 1991, $25,456$.

12. X. Zhang and P. H. McMurry, Atmos. Environ., 1992, 26A, 3305.

13. M. P. Keuken, C. A. M. Schoonebeek, A. Wensveen-Louter, and J. Slanina, Atmos. Environ., 1988, 22, 2541.

14. P. K. Simon and P. K. Dasgupta, Anal. Chem., 1993, 65, 1134.

15. M. Takeuchi, J. Li, K. J. Morris, and P. K. Dasgupta, Anal. Chem., 2004, 76, 1204.

16. S. M. R. Ullah, M. Takeuchi, and P. K. Dasgupta, Environ. Sci. Technol., 2006, 40, 962.

17. M. Takeuchi, H. Tsunoda, H. Tanaka, and Y. Shiramizu, Anal. Sci., 2011, 27, 805.

18. C. B. Boring, R. Al-Horr, Z. Genfa, P. K. Dasgupta, M. W. Martin, and W. F. Smith, Anal. Chem., 2002, 74, 1256.

19. P. K. Simon and P. K. Dasgupta, Environ. Sci. Technol., 
1995, 29, 1534

20. M. Takeuchi, H. Okochi, and M. Igawa, Atmos. Environ., 2004, 38, 4701.

21. S. Tanaka, Y. Komazaki, K. Yamagata, and Y. Hashimoto, Nippon Kagaku Kaishi, 1987, 2338.

22. A. G. Allen, R. M. Harrison, and J.-W. Erisman, Atmos.
Environ., 1989, 23, 1591

23. C.-L. Horng and M.-T. Cheng, Atmos. Res., 2008, 88, 1.

24. Z. Genfa, S. Slanina, C. B. Boring, P. A. C. Jongejan, and P. K. Dasgupta, Atmos. Environ., 2003, 37, 1351.

25. Z. Wu, M. Hu, K. Shao, and J. Slanina, Chemosphere, 2009, 76, 1028. 